CrossMark

Cite this: Polym. Chem., 2016, 7, 364

\title{
Waterborne physically crosslinked antimicrobial nanogels $\uparrow$
}

\author{
Subrata Chattopadhyay, ${ }^{a}$ Elisabeth Heine, ${ }^{a}$ Ahmed Mourran, ${ }^{a}$ Walter Richtering, ${ }^{b}$ \\ Helmut Keul*a and Martin Möller*a
}

Supramolecular nanomaterials are formed by reversible connection of different building blocks; commonly non-covalent interactions lead to the formation of these materials. In this report, we present the preparation of very stable physically crosslinked nanogels (PCNGs) via a simple one pot reaction in water as solvent. Branched poly(ethylene imine) (PEI) is functionalized with C-10 alkyl chains and azetidinium groups yielding an amphiphilic polymer, which due to the hydrophobic interaction of the alkyl chains and the ionic repulsion of the azetidinium groups forms PCNGs with high colloidal stability. As the dynamic hydrophobic interactions are the main driving force in the formation of these nanogels, the PCNG show a temperature responsive behavior with respect to the zeta potential, particle size (hydrodynamic diameter), and polydispersity index. The potential of the PCNGs to form protective coatings is shown by the formation of ultrathin films on mica and highly oriented pyrolytic graphite. Finally the antimicrobial efficacy of the PCNGs was proven against a wide range of bacteria.

Received 28th September 2015 Accepted 27th October 2015

DOI: $10.1039 / c 5 p y 01566 a$

www.rsc.org/polymers
Synthetic nanogels are generally swollen nano-sized networks, formed by amphiphilic polymers. Networks can be physically crosslinked (building blocks are connected by non-covalent interactions) or chemically crosslinked (building blocks are linked by covalent bonds). Most of the reported synthetic nanogels are chemically crosslinked as the chemical bond ensures structural integrity and stability of the nano-sized networks. Nevertheless, chemical crosslinking has some drawbacks, for example: (i) crosslinkers are often toxic enhancing the toxicity of the final material; (ii) the crosslink-density influences the properties of the final material and (iii) finally as most chemical reactions are irreversible in nature the final materials do not show any dynamic character. ${ }^{8}$ Physically crosslinked nanogels (PCNGs) are formed via non-covalent interactions of polymer chains and have advantages over the chemically crosslinked systems. For the preparation of PCNGs, there are several challenges: (i) preparation of nano-sized colloidal particles without formation of larger aggregates $(>1 \mu \mathrm{m}$ ), (ii) stability of the colloidal solution and (iii) development of a simple synthetic procedure. One pot reactions or cascade reactions in water as solvent is a prerequisite for the association by hydrophobic interaction. Further purifications of the colloidal solution should be simple. In very recent publications the formation of supramolecular nanoparticles and nanogels was reported where the building blocks are linked by non-covalent interactions (mostly host-guest kind of interactions); furthermore their potential use as delivery systems is described. ${ }^{9-16}$ Among them, synthesis of Pullulan based PCNGs (formed by hydrophobic interactions of side chains) are reported and 
their unique properties as well as their biomedical applications are described. ${ }^{17-21}$ In spite of many exciting properties of these Pullulan based PCNGs there are several drawbacks: (i) their colloidal stability is low (7-8 days), and (ii) coatings prepared by these materials absorb water from the surrounding atmosphere leading to sticky coatings, which favor biofilm formation.

In this article we report our results on PCNGs, where modified amphiphilic poly(ethylene imine)s (PEI) were used as substrates. PEI is chosen mainly for its proven benefit in different industrial and biomedical applications. ${ }^{22-24}$ In our work, the amphiphilic PEIs were prepared by post-polymerization modification of branched PEI $\left(M_{\mathrm{W}}=25 \mathrm{~kg} \mathrm{~mol}^{-1}\right)$ in water using different ratios of hydrophobic and cationic building blocks. The hydrophobic groups associate in water to form nanogels and the cationic groups on the surface of the particles prevent further agglomeration by electrostatic repulsion (Fig. 1). The nanogel dispersions were found to be stable in a large range of concentrations - also upon high dilution - and can be stored for months at room temperature without further aggregation.

This kind of nanomaterial is expected to be useful for the preparation of coatings. Natural models for such coatings are globular proteins, as for example albumin. These proteins form spherical/ellipsoidal colloids in water (the tertiary structure is formed by interactions of hydrophobic functionalities) and are useful for preparing molecular coatings. ${ }^{25-27}$ Synthetic PCNGs are expected to have similar properties because individual polymer chains associate to form nanogels in water due to hydrophobic interactions, but when the water is removed after spreading on a suitable surface, the nanogels "unfold" and form molecular coatings due to the reversibility of the hydrophobic interactions (Fig. 1).

Recently published results demonstrate that multifunctional polymers containing azetidinium groups have excellent antimicrobial properties. ${ }^{28,29}$ To understand the antimicrobial efficacy of these polymers, the minimum inhibitory concentration (MIC) against a wide range of bacteria was deter-

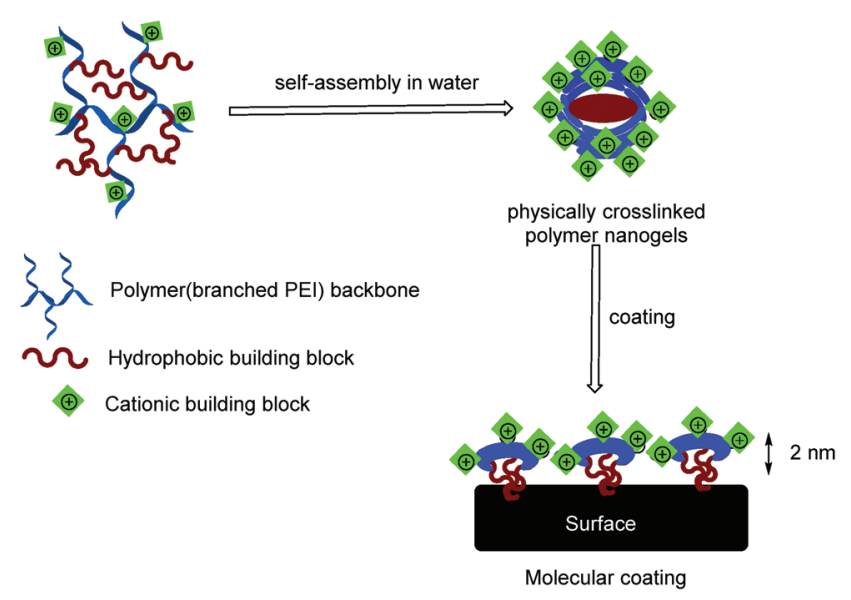

Fig. 1 Synthetic physically crosslinked nanogels and their application for molecular coatings. mined. Consequently, the antimicrobial properties of these PCNGs should be advantageous for water based coating applications. $^{30}$

\section{Experimental part}

All experimental details are given in the ESI. $\dagger$

\subsection{Nomenclature}

PEIHy ${ }_{x}^{\mathrm{d}} \mathrm{C}^{\mathrm{az}}{ }_{y}$ stands for multifunctional PEI, where $x \%$ of the primary amine groups were modified with a hydrophobic coupler (Hy) containing the decyl (C-10) chain (d) and $y \%$ of the primary amine groups were modified with the cationic (C) bifunctional coupler (az stands for azetidinium groups).

\section{Results and discussion}

An easy one pot synthetic approach to prepare waterborne PCNGs is presented, where amphiphilic PEIs with hydrophobic and cationic building blocks self associate to form nanogels by hydrophobic interactions of the long alkyl chains (C-10); the nanogels being stabilized by the azetidinium groups at the surface. These amphiphilic PEIs, containing alkyl chains and cationic azetidinium groups were prepared in a one pot reaction in water, via post-polymerization modification of branched PEI using the coupler concept (Scheme 1). ${ }^{31,32}$ The advantage of this approach is that, starting from the synthesis of the couplers from commercially available chemicals to the preparation of the functional polymers all reaction steps are performed in the same reaction vessel, in water as solvent, without intermediate purification (experimental details are given in the Experimental section in SI $1 \dagger$ ).

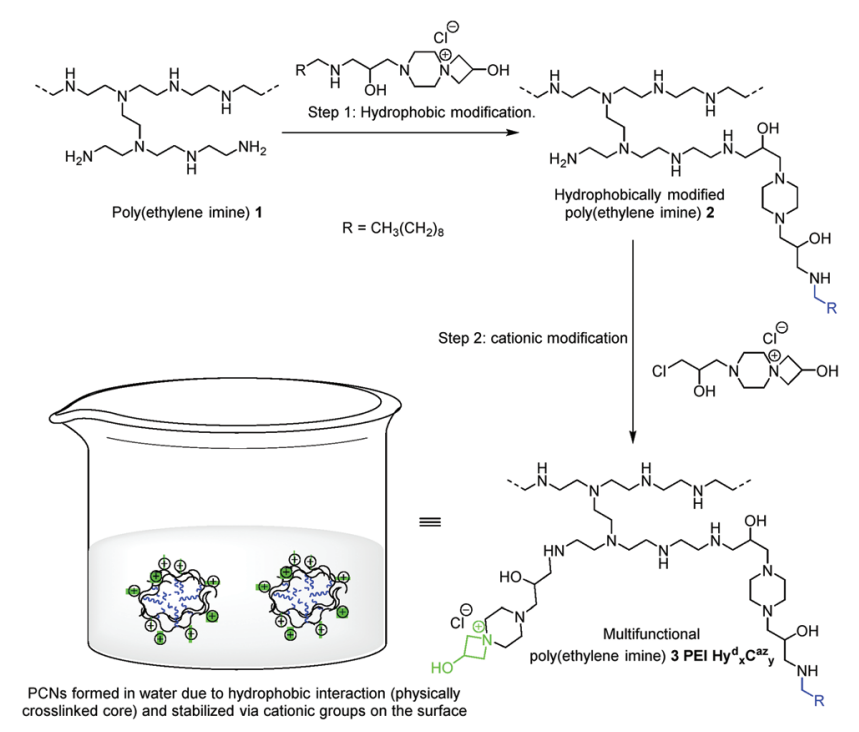

Scheme 1 Synthesis of multifunctional PEI nanogels in water using the coupler approach. 
After preparing the two couplers, the multifunctional nanogels were prepared in two steps. PEI was reacted first with the hydrophobic coupler, containing an azetidinium functional group at one end and a decyl chain (C-10) at the other end. During the reaction the azetidinium groups react with the primary amine groups by ring opening, leading to hydrophobically modified PEI 2. In the next step, hydrophobically modified PEI was reacted with the bi-functional coupler to link azetidinium groups to the polymer backbone resulting in the multifunctional PEI 3.

Three polymers were prepared with different hydrophobic to cationic ratios - PEIHy ${ }_{10}^{\mathrm{d}} \mathrm{C}^{\mathrm{az}}{ }_{15}$, PEIHy ${ }_{12.5}^{\mathrm{d}} \mathrm{C}^{\mathrm{az}}{ }_{12.5}$ and PEI$\mathrm{Hy}^{\mathrm{d}}{ }_{15} \mathrm{C}^{\mathrm{az}}{ }_{10}$; the ratio of decyl chains to azetidinium (cationic) groups was $1: 1.5,1: 1,1.5: 1$, respectively. The degree of functionalization (both hydrophobic and cationic) was adjusted using the predetermined ratio of PEI and couplers. In the final product the functional groups were quantified by ${ }^{1} \mathrm{H}$ NMR spectroscopy (Fig. SI $1 \mathrm{~B}^{\dagger}$ ). The characteristic peaks for the protons (3-11) of the $\mathrm{C}-10$ chains were found at $\delta=$ 1.8-0.6 ppm and the characteristic protons for the azetidinium groups were found at $\delta=5-4 \mathrm{ppm}$. The ratio of the hydrophobic: cationic functionalization was calculated using the integration ratio of the protons at $\delta=4.15 \mathrm{ppm}\left(\mathrm{H}^{2}\right)$ and $\delta=0.8 \mathrm{ppm}\left(\mathrm{H}^{11}\right)$ (ESI, Table SI $\left.2 \dagger\right)$.

The multifunctional PEI, containing both hydrophobic (decyl) and cationic (azetidinium) groups, spontaneously self assembled in water to form stable physically crosslinked nanogels due to strong hydrophobic interactions of the C-10 chains. The cationic azetidinium groups remain at the surface and ensure the stability of these particles by a suitable balance between the hydrophobic interaction and cationic repulsion. The PCNGs with different hydrophobic to cationic ratio - PEI$\mathrm{Hy}^{\mathrm{d}}{ }_{10} \mathrm{C}^{\mathrm{Az}}{ }_{15}$, PEIHy ${ }_{12.5}^{\mathrm{d}} \mathrm{C}^{\mathrm{Az}}{ }_{12.5}$ and PEIHy ${ }_{15}^{\mathrm{d}} \mathrm{C}^{\mathrm{Az}}{ }_{10}$ - have similar characteristics. The current report will discuss the results obtained for PEIHy ${ }_{12.5}^{\mathrm{d}} \mathrm{C}^{\mathrm{Az}}{ }_{12.5}$; detailed characterization for all three nanogels is given in ESI. $\dagger$

The PCNGs were characterized in detail by light scattering experiments, both by dynamic and by static light scattering (Table 1). The average hydrodynamic radius of the PCNGs determined by DLS in ultrapure water at $25{ }^{\circ} \mathrm{C}$, (concentration $\left.1 \mathrm{mg} \mathrm{mL}{ }^{-1}\right)$ was $R_{\mathrm{h}}=95 \mathrm{~nm}( \pm 3 \mathrm{~nm})$ and the dispersity index amounted to $0.2( \pm 0.03)$. From static light scattering, the second virial coefficient $\left(A_{2}\right)$, the radius of gyration $\left(R_{\mathrm{g}}\right)$ and the average molecular weight of the aggregates (PCNGs) were determined using Berry plots (ESI, Fig. SI $5 \dagger$ ). The Berry plot -

Table 1 Results of the light scattering experiments at lower and higher temperature (solvent : water)

\begin{tabular}{llllllll}
\hline $\begin{array}{l}T \\
\left({ }^{\circ} \mathrm{C}\right)\end{array}$ & $\begin{array}{l}R_{\mathrm{h}}(\mathrm{nm}) \\
( \pm 3 \mathrm{~nm})\end{array}$ & $\begin{array}{l}\text { PDI } \\
( \pm 0.03)\end{array}$ & $\begin{array}{l}R_{\mathrm{g}}(\mathrm{nm}) \\
( \pm 5 \mathrm{~nm})\end{array}$ & $\begin{array}{l}R_{\mathrm{g}} / R_{\mathrm{h}} \\
\left.(\mathrm{mol} \mathrm{mL} \mathrm{g})^{-1}\right)\end{array}$ & $M_{\mathrm{w},(\mathrm{agg})}$ & $N_{\mathrm{agg}}{ }^{a}$ \\
\hline 25 & 95 & 0.2 & 236 & 2.48 & $-7.91 \times 10^{-7}$ & $61 \times 10^{6}$ & 2271 \\
50 & 112 & 0.07 & 136 & 1.21 & $-1.54 \times 10^{-6}$ & $82 \times 10^{6}$ & 3055 \\
${ }^{a} N_{\mathrm{agg}}=$ & $M_{\mathrm{w},(\mathrm{agg})} / M_{\mathrm{w},(\mathrm{GPC})}$. & & & & \\
\end{tabular}

and not the conventional Zimm plot was chosen due to the big size of the PCNGs. The value of $A_{2}\left(-7.91 \times 10^{-7}\right)$ is very small due to the high molar mass of the particles. ${ }^{33}$ The value obtained for the radius of gyration $R_{\mathrm{g}}=236 \mathrm{~nm}$ is much higher than the hydrodynamic radius $R_{\mathrm{h}}$. The shape factor, determined from the ratio of $R_{\mathrm{g}} / R_{\mathrm{h}}$ is $\sim 2.5$, possibly due to the elongated and irregular shape of the larger nanogel particles. ${ }^{28}$ The average molar mass of the aggregates (PCNGs) was determined to be $M_{\mathrm{w}}$ agg $=61.1 \times 10^{6} \cdot{ }^{34,35}$ The number of polymer chains $\left(N_{\text {agg }}\right)$, connected to form single PCNGs was obtained by dividing $M_{\mathrm{w}}$, agg by the assumed $M_{\mathrm{w}}$ of the polymers obtained from GPC (ESI, Table SI $3 \dagger$ ), and was calculated to be $N_{\text {agg }}=2271 .^{36}$

The colloidal stability of these particles is also obvious from the zeta potential, $\zeta=73 \mathrm{mV}( \pm 5 \mathrm{mV})$. Here we also note that the average hydrodynamic radius determined by DLS is biased to the larger particle - this is due to a known limitation of DLS, where the hydrodynamic radius is determined as a function of scattering intensity, which is proportional to radius power of six. ${ }^{37,38}$ The CONTIN plots obtained by DLS also show the presence of particles with diameters in the range of $40 \mathrm{~nm}$ to $700 \mathrm{~nm}$ (Fig. SI 3 and SI $4 \dagger$ ). Since temperature influences the hydrophobic interaction, which is the main driving force for the formation of the PCNGs, a temperature responsive behavior is expected. Temperature dependent studies of the PCNGs were performed in the range of $10^{\circ} \mathrm{C}$ to $60{ }^{\circ} \mathrm{C}$ using a colloidal solution of $1 \mathrm{mg} \mathrm{mL}^{-1}$ concentration (Fig. 2).

The hydrodynamic diameter of the nanoparticles increases with increasing temperature (Fig. 2A and Table 1). This observation leads to the conclusion that at higher temperature smaller aggregates associate due to the increase of hydrophobic interaction. Larger aggregates of optimum sizes are formed leading to a lower surface energy and consequently to a thermodynamically more stable system. ${ }^{39,40}$ This explanation

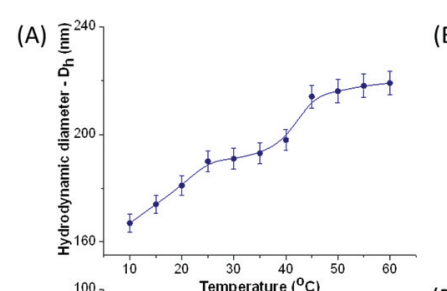

(C)
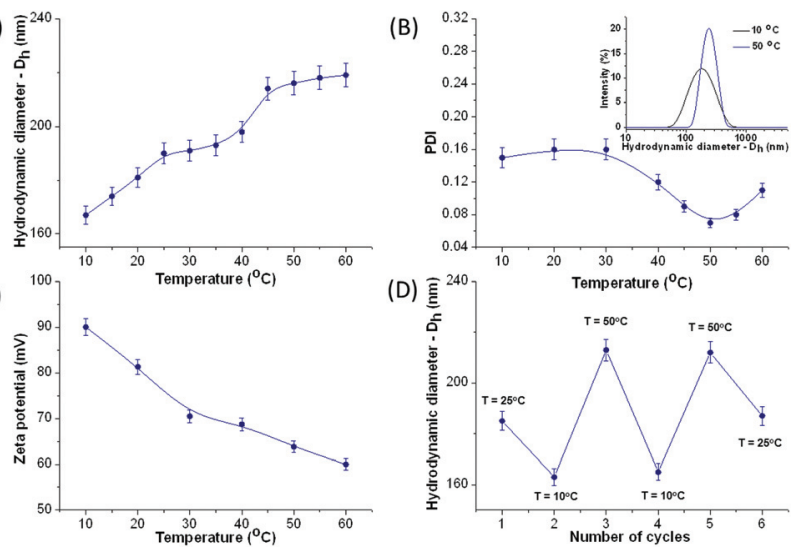

Fig. 2 Effect of temperature on the PCNGs: (A) hydrodynamic diameter vs. temperature, (B) polydispersity index (PDI) vs. temperature (insert CONTIN plots at $10^{\circ} \mathrm{C}$ and $50^{\circ} \mathrm{C}$ ), (C) zeta potential vs. temperature, (D) reversible change of the particle size with temperature. 
is supported by the fact that the molecular weight of the aggregates increased at higher temperature (Table 1). Further, increasing temperature leads to a decrease of the particle dispersity (PDI) with a minimum at $45^{\circ} \mathrm{C}$ to $55^{\circ} \mathrm{C}$ (Fig. 2B) and consequently a decrease in $R_{\mathrm{g}} / R_{\mathrm{h}}$ (Table 1 ).

A decrease of the zeta potential with increasing temperature also supports the association of the smaller aggregates to form larger aggregates, leading to a decrease of the total surface area and consequently a decrease of the net charge (Fig. 2C). As the hydrophobic interaction is dynamic and reversible in nature, the temperature responsive behavior of the PCNGs is expected to be reversible. To check the reversibility of this behavior, the size of the particles was measured at different temperatures between $10{ }^{\circ} \mathrm{C}$ and $50{ }^{\circ} \mathrm{C}$ as shown in Fig. 2D. The same size of the PCNGs at a particular temperature was observed during different heating and cooling cycles, proving that the temperature responsive behavior of the particles is reversible.

As shown in the ESI document (Table SI 4-6†) the diameter of PCNGs does not change significantly with the polymer concentration $\left(0.02-2 \mathrm{mg} \mathrm{mL}^{-1}\right)$. Furthermore, the colloidal solutions are stable in time (1-120 days) and even after addition of salt ( $\mathrm{NaCl}$ concentration up to $10 \mathrm{wt} \%$ ).

The structure of the PCNGs was visualized by cryo-TEM which enables to observe the PCNG in the native state. Fig. 3 shows representative cryo-TEM micrographs. Basically the presence of small and large particles with an average radius of ca. $25 \mathrm{~nm}$ (Fig. 3A) and $75 \mathrm{~nm}$ (Fig. 3B), is demonstrated. Obviously the size difference is due to the local concentration. Fig. 3A represents the smallest PCNGs in the sample and their self-association leads to the larger ones. Indeed, the radius of a single modified PEI chain is approximately $7 \mathrm{~nm}$ (ESI, SI $6 \dagger) .{ }^{41}$ We conclude that the smallest PCNGs result from association of approximately 3 to 4 hydrophobically modified PEI chains. It is remarkable that an increase of the concentration does not lead to precipitation even up to $50 \mathrm{wt} \%$, ensuring the high stability of the colloidal solution. We can therefore assume that the softness of the nanogel concurs with electrostatic repulsion providing a means to limit the association and to prevent precipitation as macroscopic gel.

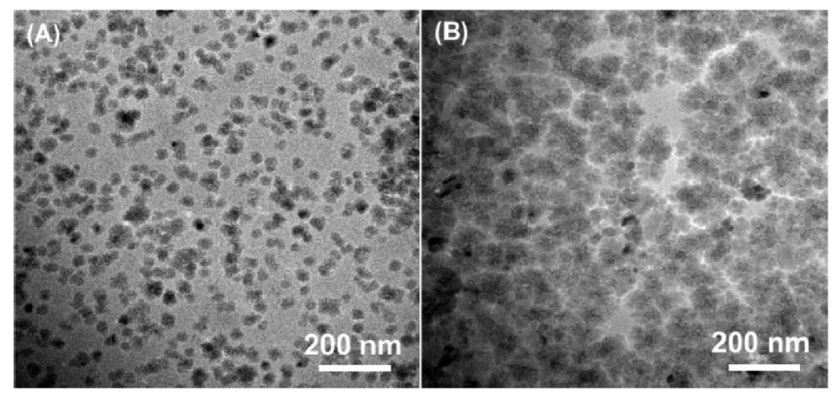

Fig. 3 Cryo-TEM images of PCNG (PEIHy ${ }_{12.5} \mathrm{C}^{\mathrm{Az}}{ }_{12.5}$ ): showing the morphology of the PCNGs: (A) smaller PCNGs with an average radius of ca. $25 \mathrm{~nm}$ (B) larger PCNGs with an average radius of ca. $75 \mathrm{~nm}$.
To show the potential of the PCNGs to form protective coatings, a freshly cleaved mica or highly oriented pyrolytic graphite (HOPG) surface were coated with a diluted polymer solution and analyzed by scanning force microscopy SFM. We expect that the difference in surface polarity helps to unveil structural details of the polymer. Fig. 4 shows a typical film morphology depending on the polymer concentration.

Regardless of the substrate polarity, the polymer spreads uniformly and the phase images do not indicate surface heterogeneity (not shown). However, the details of the polymer structure begin to manifest for molecular films, namely thickness below $5 \mathrm{~nm}$. Indeed, homogeneous coverage with fine blob-like textures with a mean height of $2 \mathrm{~nm}$ on Mica (Fig. 4A) and a slightly larger height of $2.5 \mathrm{~nm}$ on HOPG is observed (Fig. 4C). This fine texture and the molecular thickness indicate that the nanogel unfolds upon adsorption on solid interface. The thickness of this interfacial layer is defined by the local adjustment of the molecular conformation. We provide evidence through careful observation of few molecules deposited from an extradiluted solution, see micrographs in Fig. 4B and D. Obviously, polar surfaces such as mica favor spreading of the poly(ethylene imine) backbone, the $n$-decyl side chains resist and adapt their conformation. The result is a central aliphatic moiety
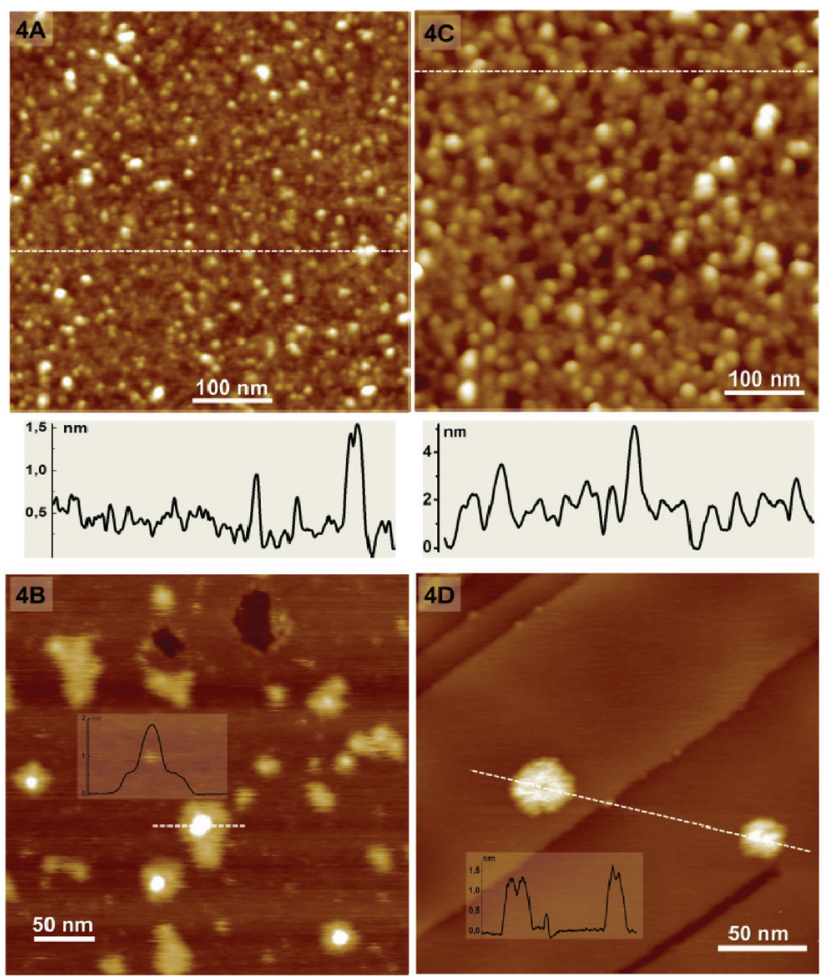

Fig. 4 AFM height-images of ultrathin films deposited on mica (A-B) and on HOPG (C-D). The micrographs of the upper row have been obtained by coating a solution of $0.01 \mathrm{~g} \mathrm{~L}^{-1}$ and the bottom row are from solutions of $0.001 \mathrm{~g} \mathrm{~L}^{-1}$. Note the profile, as indicated by the line, and the scale difference indicates spreading of the polymer onto the Mica in comparison to HOPG surface. The dark contrast (B) with $0.1 \mathrm{~nm}$ in depth is due to water contamination from the atmosphere. 
Table 2 Antimicrobial activity (MIC: lowest polymer concentration resulting in 100\% growth inhibition during 20 h) and hemolytic activity of the $\mathrm{PEIHy}{ }_{12.5}^{\mathrm{d}} \mathrm{C}^{\mathrm{az}}{ }_{12.5}$ : their comparison with the unmodified $\mathrm{PEI}$ and earlier reported best antimicrobial modified $\mathrm{PEIs}\left(\mathrm{PEI}_{25}-\mathrm{Ql} \mathrm{I}_{12.5} \mathrm{Q} 12 \mathrm{Br}{ }_{12.5}{ }^{41}\right.$ $\mathrm{PEI}_{25}-\mathrm{Q} 12 \mathrm{Br}_{12.5}{ }^{42}$ Fig. SI 7)

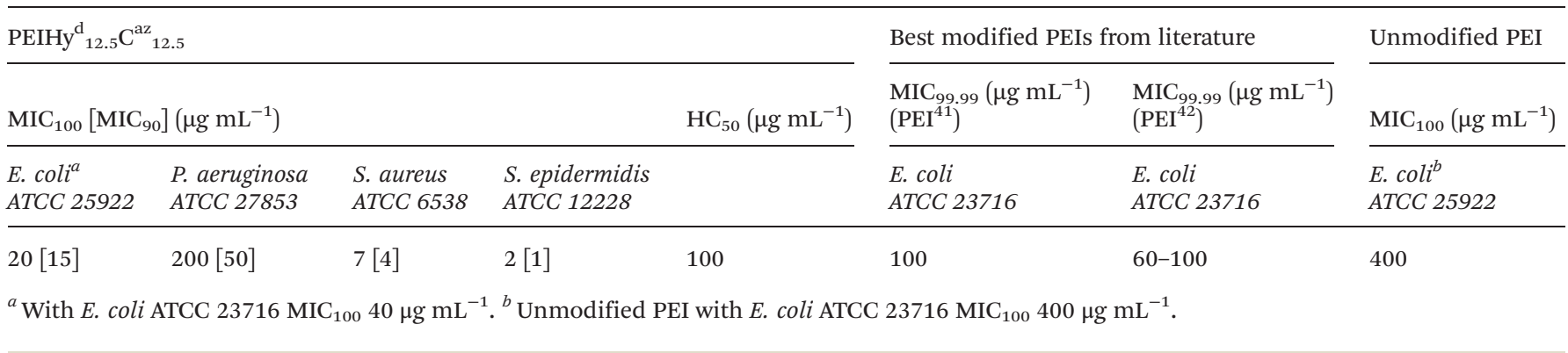

embedded in molecularly spread PEI (see insert profile in Fig. 4B). The reverse occurs on hydrophobic HOPG surface, the branched poly(ethylene imine) opposes to the adsorption and spreading of the aliphatic side chains. This results in molecular islands with defined height (see insert profile in Fig. 4D). We note that the profile is compatible with the length of $n$-decyl chains which is $0.87 \mathrm{~nm}$ covalently linked to the branched structure of the poly(ethylene imine) backbone. These experiments demonstrate that the PCNGs can potentially be useful as a material for molecular coatings.

Finally, the antimicrobial activity of the PCNGs was studied in solution against a wide range of bacteria. The minimum inhibitory concentration was determined as the minimum concentration required to inhibit $100 \%$ of bacterial growth within the time monitored $(20 \mathrm{~h})$. To compare the antimicrobial efficacy of the PCNGs with some of the best antimicrobial polymers reported in literature, we also calculate $\mathrm{MIC}_{90}$ (the concentration required to $90 \%$ bacterial growth inhibition), as this is the most frequently used term in literature (Table 2). To understand the selectivity of the polymer to affect bacterial cells and mammalian cells, the hemolysis test was also performed and the concentration required for $50 \%$ lysis of red blood cells was determined. The results are summarized in Table 2. It was found that the polymer is highly active against a wide range of bacteria to inhibit their growth completely at significantly low MIC values. The polymer was found to be more effective against gram positive bacteria compared to gram negative bacteria. It was also shown that the MIC of the two different gram negative species $E$. coli and $P$. aeruginosa differ by a factor of 10 . P. aeruginosa secretes an extracellular matrix made from muco-polysaccharides (a highly flexible gel, e.g. from alginate stabilized by $\mathrm{Ca}^{2+}$ ions). This matrix is able to bind charged molecules and water, thus, it is likely that it will bind part of the polymer molecules, therefore, higher amounts of polymer are needed to inhibit the growth of $P$. aeruginosa compared with $E$. coli. ${ }^{43,44}$ This explanation can be supported by the fact that nonfunctionalized PEI has a better antimicrobial efficacy against $P$. aeruginosa compared to the functionalized PCNGs (Table SI $8 \dagger$ ). The much higher value of $\mathrm{HC}_{50}$ compared to their $\mathrm{MIC}_{100}$ (except $P$. aeruginosa) proved that the polymers have a good selectivity to differentiate between mammalian cells and bacterial cell wall.
The overall antimicrobial efficacy and selectivity of the current polymers is much higher when compared with unmodified PEI (Table SI $8 \dagger$ ) and approximately by a factor of 3-5 when compared with the earlier reported modified antimicrobial PEIs ${ }^{41,42}$ (Table 2) and also higher/comparable with some of the best synthetic antimicrobial peptidomimetics reported in literature. ${ }^{45,46}$ The higher antimicrobial efficacy (compared to other reported modified PEIs ${ }^{41,42}$ ) of the modified PEI aggregates (PCNGs) can be attributed to the fact that aggregates rather than single oligomers result in extensive damage (formation of water channel or pores) of the bacterial envelope. ${ }^{47}$ Nanostructure formation leads to an increased local concentration of the cationic moiety prior to contacting a cell envelope leading to a stronger antimicrobial effect compared to single polymer molecules. ${ }^{48,49}$

\section{Conclusion}

A one pot synthetic approach to prepare multifunctional PEIs in water, with a defined ratio of hydrophobic (C-10 chains) and cationic building blocks is presented, which spontaneously self assemble to form very stable PCNGs (stability over months was observed). The PCNGs show a temperature responsive behavior - the size increases with increasing temperature. Furthermore it was found that the change of the hydrodynamic diameter with temperature is reversible as a consequence of the reversibility of the hydrophobic interaction. PCNGs were used to prepare molecular films on surfaces with different polarity: homogeneous surface coverage with fine blob-like textures with a mean height of $\sim 2 \mathrm{~nm}$ on Mica and a slightly larger height of $\sim 2.5 \mathrm{~nm}$ on HOPG is observed. This result proves the potential of these nanogels for the preparation of thin film coatings. Finally PCNGs were found to have excellent antimicrobial activity against a wide range of different bacteria - the MIC values are comparable or better than some of the best synthetic antimicrobial polymers reported in literature. Furthermore these PCNGs have a good selectivity to differentiate between bacterial cell membranes and mammalian cell membranes. The selectivity of the PCNG is an important parameter for the future applications of these PCNGs. 


\section{Acknowledgements}

The authors thank the Deutsche Forschungsgemeinschaft for support within SFB 985 "Functional microgels and microgel systems" and the European Union's Horizon 2020 research and innovation program under the Marie Sklodowska-Curie grant agreement No 642687: BIOGEL. The authors thank Dr Rahimi Khosrow for cryo-TEM measurements.

\section{References}

1 T. F. A. de Greef and E. W. Meijer, Nature, 2008, 453, 171.

2 X. Yan, F. Wang, B. Zheng and F. Huang, Chem. Soc. Rev., 2012, 41, 6042 .

3 S. Zhang, Nat. Biotechnol., 2003, 21, 1171.

4 D. Philip and J. F. Stoddart, Angew. Chem., Int. Ed. Engl., 1996, 35, 1154.

5 J. Ramos, J. Forcada and R. Hidalgo-Alvarez, Chem. Rev., 2014, 114, 367.

6 A. L. Sisson and R. Haag, Soft Matter, 2010, 6, 4968.

7 B. R. Saunders and B. Vincent, Adv. Colloid Interface Sci., 1999, 80, 1.

8 D. Klinger and K. Landfester, Polymer, 2012, 53, 5209.

9 A. Harada, Y. Takashima and H. Yamaguchi, Chem. Soc. Rev., 2009, 38, 875.

10 Y. Liu, J. Shi, Y. Chen and C.-F. Ke, Angew. Chem., Int. Ed., 2008, 47, 7293.

11 Y. Liu, K. Liu, Z. Wang and X. Zhang, Angew. Chem., Int. Ed., 2010, 49, 6576.

12 U. Rauwald and O. A. Scherman, Angew. Chem., Int. Ed., 2008, 47, 3950.

13 X. Chen, L. Chen, X. Yao, Z. Zhang, C. He, J. Zhang and C. He, Chem. Commun., 2014, 50, 3789.

14 J. Li, Z. Su, H. Xu, X. Ma, J. Yin and X. Jiang, Macromol., 2015, 48, 2022.

15 X. Yao, L. Chen, X. Chen, Z. Zhang, H. Zheng, C. He, J. Zhang and X. Chen, ACS Appl. Mater. Interfaces, 2014, 6, 7816.

16 T. Akagi, P. Piyapakorn and M. Akashi, Langmuir, 2012, 28, 5249.

17 A. V. Kabanov and S. V. Vinogradov, Angew. Chem., Int. Ed., 2009, 48, 5418.

18 T. Nochi, Y. Yuki, H. Takahushi, S. Sawada, M. Mejima, T. Kohda, N. Harada, G. Kong, A. Sato, N. Kataoka, D. Tokuhara, S. Kurokawa, Y. Takahashi, H. Tsukada, S. Kozaki, K. Akiyoshi and H. Kiyono, Nat. Mater., 2010, 9, 572 .

19 S. Kageyama, S. Kitano, M. Hirayama, Y. Nagata, H. Imai, T. Shiraishi, K. Akiyoshi, A. M. Scott, R. Murphy, E. W. Hoffmann, L. J. Old, N. Katayama and H. Shiku, Cancer Sci., 2008, 99, 601.

20 K. Kuroda, K. Fujimoto, J. Sunamoto and K. Akiyoshi, Langmuir, 2002, 18, 3780.

21 A. Guyomard, E. De, T. Jouenne, J. J. Malandain, G. Muller and K. Glinel, Adv. Funct. Mater., 2008, 18, 758.
22 Y. Chen, N. Ballard and S. A. F. Bon, Polym. Chem., 2013, 4, 387.

23 H. Mimi, K. M. Ho, Y. S. Siu, A. Wu and P. Li, J. Controlled Release, 2012, 158, 123.

24 D. Xu, J. Yu, Y. Liu, H. Sun, J. Xu, K. Sheng, S. Yao, Y. Xu and H. Lu, Int. J. Nanosci., 2006, 5, 753.

25 Y. Wu, S. Chakrabortty, R. A. Gropeanu, J. Wilhelmi, Y. Xu, K. S. Er, S. L. Kuan, K. Koyonov, Y. Chan and T. Weil, J. Am. Chem. Soc., 2010, 132, 5012.

26 G. J. Quinlan, G. S. Martin and T. W. Evans, Hepatology, 2005, 41, 1211.

27 I. Lee and K. Akiyoshi, Biomaterials, 2004, 25, 2911.

28 S. Chattopadhyay, E. Heine, H. Keul and M. Möller, Polymer, 2014, 6, 1618.

29 S. Chattopadhyay, E. T. Heine, H. Keul and M. Möller, Macromol. Biosci., 2014, 14, 1116.

30 E. Faure, C. F. Daudre, T. S. Lanero, C. Vreuls, G. Zocchi, C. V. D. Weerdt, J. Martial, C. Jerome, A. S. Duwez and C. Detrembleur, Adv. Funct. Mater., 2012, 22, 5271.

31 S. Chattopadhyay, H. Keul and M. Möller, Macromolecules, 2013, 46, 638.

32 S. Chattopadhyay, H. Keul and M. Möller, Green Chem., 2013, 15, 3135.

33 H. Yamakawa, Modern Theory of Polymer Solutions, Haroer \& Row, New York, 1971.

34 A. K. Brewer and A. M. Striegel, Analyst, 2011, 136, 515.

35 W. Burchard and W. Richtering, Prog. Colloid Polym. Sci., 1989, 80, 151.

36 W. Burchard, Adv. Polym. Sci., 1999, 143, 113.

37 K. Imanishi and Y. Einaga, J. Phys. Chem. B, 2005, 109, 7574.

38 V. Vogel, J. F. Gohy, B. G. G. Lohmeijer, J. A. V. D. Broek, W. Hasse, U. S. Schubert and D. Schubert, J. Polym. Sci., Part A: Polym. Chem., 2003, 41, 3159.

39 X. Li, K. Y. Mya, X. Ni, C. He, K. W. Leong and J. Li, J. Phys. Chem. B, 2006, 110, 5920.

40 K. Nagahama, M. Hashizume, H. Yamamoto, T. Ouchi and Y. Ohya, Langmuir, 2009, 25, 9734.

41 N. Pasquier, H. Keul, E. Heine, M. Moeller, B. Angelov, S. Linser and R. Willumeit, Macromol. Biosci., 2008, 8, 903.

42 Y. He, E. Heine, N. Keusgen, H. Keul and M. Möller, Biomacromolecules, 2012, 13, 612.

43 P. Tielen, H. Kuhn, F. Rosenau, K. E. Jaeger, H. C. Flemming and J. Wingender, BMC Microbiol., 2013, 13, 159.

44 I. A. MacDonald and M. J. Kuehn, J. Bacteriol., 2013, 195, 2971.

45 K. Lienkamp, A. E. Madkour, A. Musante, C. F. Nelson, K. Nuesslein and G. N. Tew, J. Am. Chem. Soc., 2008, 130, 9836-9843.

46 K. Lienkamp and G. N. Tew, Chem. - Eur. J., 2009, 15, 11784-11800.

47 E. H. Hill, K. Stratton, D. G. Whitten and D. G. Evans, Langmuir, 2012, 28, 14849.

48 F. Nederberg, Y. Zhang, J. P. K. Tan, K. Xu, H. Wang, C. Yang, S. Gao, X. D. Guo, K. Fukushima, L. Li, J. L. Hedrick and Y. Y. Yang, Nat. Chem., 2011, 3, 409-414.

49 J. Chen, F. Wang, Q. Liu and J. Du, Chem. Commun., 2014, 50, 14482-14493. 